\title{
Region-Specific Spike-Frequency Acceleration in Layer 5 Pyramidal Neurons Mediated by Kv1 Subunits
}

\author{
Mark N. Miller, Benjamin W. Okaty, and Sacha B. Nelson \\ Biology Department, Brandeis University, Waltham, Massachusetts 02453
}

\begin{abstract}
Separation of the cortical sheet into functionally distinct regions is a hallmark of neocortical organization. Cortical circuit function emerges from afferent and efferent connectivity, local connectivity within the cortical microcircuit, and the intrinsic membrane properties of neurons that comprise the circuit. While localization of functions to particular cortical areas can be partially accounted for by regional differences in both long range and local connectivity, it is unknown whether the intrinsic membrane properties of cortical cell types differ between cortical regions. Here we report the first example of a region-specific firing type in layer 5 pyramidal neurons, and show that the intrinsic membrane and integrative properties of a discrete subtype of layer 5 pyramidal neurons differ between primary motor and somatosensory cortices due to region- and cell-type-specific Kv1 subunit expression.
\end{abstract}

Key words: neocortex; Kv1; firing type; pyramidal cell; motor cortex; electrophysiology

\section{Introduction}

Contemporary understanding of neocortical circuitry emerged from a dialogue between two views, one emphasizing the localization of particular functions to particular cortical regions and the other emphasizing similarities shared by all neocortical circuits (Nelson, 2002; Douglas and Martin, 2004). Circuit activity arises from complex interactions among afferent inputs, the intrinsic properties of the circuit's cells, and local synaptic connectivity among those cells, and functional differences between cortical regions could emerge from differences in any or all of these features.

Seminal "rewiring" experiments demonstrated that cortical circuits are capable of inheriting function from their afferent inputs (Sur et al., 1988; Metin and Frost, 1989). Furthermore, the basic properties of neocortical synapses are invariant across regions (Myme et al., 2003). Although these findings support the idea that neocortical microcircuitry is canonical and can be endowed with function by extrinsic input, there is substantial evidence that fundamental elements of cortical circuits differ between functionally distinct cortical regions. Primary motor cortex (M1), for example, lacks a distinct layer 4 (Donoghue and Wise, 1982) and has a correspondingly elaborated layer 5, while the adjacent primary somatosensory cortex (S1) exhibits a pronounced layer 4 that is the major recipient of thalamocortical afferents, and $\mathrm{M} 1$ but not $\mathrm{S} 1$ is capable of sustaining $10 \mathrm{~Hz}$ oscil-

Received June 25, 2008; revised 0ct. 15, 2008; accepted 0ct. 15, 2008.

This work was supported by National Institute of Mental Health Grant R01-MH06638 (S.B.N.) and National Institute of Neurological Disorders and Stroke Grant5F31-NS055516 (M.N.M.). We thankmembers of the Nelson and Turrigiano laboratories for commentary and fruitful discussion, and two anonymous reviewers for very constructive criticism.

Correspondence should be addressed to Sacha B. Nelson, Biology Department, MS-008, Brandeis University, 415 South Street, Waltham, MA 02453. E-mail: nelson@brandeis.edu.

DOI:10.1523/JNEUROSCI.2940-08.2008

Copyright $\odot 2008$ Society for Neuroscience ～0270-6474/08/2813716-11\$15.00/0 lations both in vivo (Castro-Alamancos, 2000) and in a disinhibited slice preparation (Castro-Alamancos and Tawara-Hirata, 2007; Castro-Alamancos et al., 2007). Additionally, both the synaptic dynamics (Hempel et al., 2000) and intrinsic connectivity (Wang et al., 2006) of prefrontal cortex are specialized to provide a substrate for persistent activity, indicating that region-specific function can be partially due to regional specialization of cortical microcircuitry. Whether neuronal intrinsic membrane properties are similarly specialized is unknown.

The catalog of cortical cell types has grown immensely over the last decade as increasingly refined morphological, physiological, and molecular approaches have been brought to bear. Although early anatomical work established that all cortical circuits are composed of excitatory pyramidal cells and a diverse set of interneurons, more recent studies demonstrate that a cell type's dendritic complexity, spine count (Elston, 2000, 2002; Elston and DeFelipe, 2002), and spine morphology (Benavides-Piccione et al., 2002) vary rostrocaudally across the cortical sheet, and recent attempts to correlate gene expression and electrophysiological properties suggest that many differences between cell types are accounted for by differences in voltage-gated potassium channel expression (Toledo-Rodriguez et al., 2004; Sugino et al., 2006).

These findings strongly suggest that some cellular and subcellular elements of neocortical microcircuitry are region specific, but an important outstanding question is whether the intrinsic membrane and integrative properties of a discrete and identified cell type are regionally specialized. Here, we directly address this question by characterizing the firing type and intrinsic membrane properties of pyramidal tract-projecting (PT) layer 5 pyramidal cells in $\mathrm{M} 1$ and S1, two adjacent but functionally divergent cortical regions. Our results indicate the presence of a unique cell-type- and region-specific "accelerating" firing type in M1 that is mediated by cell-type- and region-specific Kv1 subunit expression. 


\section{Materials and Methods}

Electrophysiology. All experiments were conducted in accordance with National Institutes of Health guidelines for animal use and authorized by the Brandeis University animal use committee. Chemicals were obtained from Sigma unless otherwise noted. Acute slices were prepared according to conventional methods as previously described (Hattox and Nelson 2007). Briefly, young adult mice (p23-p30) of the Thyl-YFPH transgenic line were anesthetized with isoflurane and acute $300 \mu \mathrm{m}$ coronal slices containing $\mathrm{M} 1, \mathrm{~S} 1$, or both regions were prepared in cold $\left(1-3^{\circ} \mathrm{C}\right)$ oxygenated artificial CSF (ACSF) containing (in mM): $126 \mathrm{NaCl}, 3 \mathrm{KCl}, 2$ $\mathrm{MgSO}_{4}, 1 \mathrm{NaH}_{2} \mathrm{PO}_{4}, 25 \mathrm{NaHCO}_{3}, 2 \mathrm{CaCl}_{2}$, with osmolarity adjusted to $\sim 320 \mathrm{mOsm}$ with dextrose. Slices were incubated at $37^{\circ} \mathrm{C}$ for $30 \mathrm{~min}$ and then allowed to relax to room temperature for at least another $30 \mathrm{~min}$ before recording. During recordings, slices were continuously perfused with $33-35^{\circ} \mathrm{C}$ ACSF supplemented with $50 \quad \mu \mathrm{M}$ 2-amino-5phosphonovaleric acid (AP-V) and $20 \mu \mathrm{M}$ 6,7-dinitroquinoxaline-2,3dione (DNQX) to block glutamatergic synaptic transmission, and either $20 \mu \mathrm{M}$ bicuculline methobromide or $50 \mu \mathrm{M}$ picrotoxin to block $\mathrm{GABA}_{\mathrm{A}}$ receptors. Tetrodotoxin (TTX, $2 \mu \mathrm{M}$ ), ZD7288 (100 $\mu \mathrm{M}$, Tocris), nifedipine $(30-50 \mu \mathrm{m})$, and $\mathrm{NiCl}_{2}(100 \mu \mathrm{M})$ were added to the recording ACSF during voltage-clamp experiments to block fast sodium, $I_{\mathrm{H}}$, and voltagegated calcium currents, respectively. DTX-I (50-100 nM), MTX (10-15 $\mathrm{nM}$ ), and TiTX (25-35 nм), all obtained from Alomone Labs, were bath applied to isolate Kv1 currents. Cells were identified as YFPH or PT under epifluorescence and whole-cell recordings were obtained with visual guidance under IR-DIC illumination. The boundary between M1 and $\mathrm{S} 1$ was readily identified in slices according to the criteria of Franklin and Paxinos (2003) and specifically by (1) the characteristically thicker layer 5 in M1 apparent in both YFPH and animals injected with retrograde tracer and (2) the presence of barrels in S1. Distinguishing between $\mathrm{M} 1$ and $\mathrm{M} 2$ was more difficult, and although most motor cortex recordings were obtained from $\mathrm{M} 1$ cells, biocytin staining revealed that a small number were obtained from the M1/M2 border. Because data from these cells were identical to those from M1, they were pooled together. Recording pipettes with a tip resistance of 3-6 $\mathrm{M} \Omega$ were filled with an internal solution containing (in $\mathrm{mm}$ ): $100 \mathrm{~K}$-gluconate, $20 \mathrm{KCl}, 10$ HEPES, 4 Mg-ATP, $0.3 \mathrm{Na}$-GTP, $10 \mathrm{Na}$-phosphocreatine, and $0.25 \%$ biocytin, adjusted to $\sim 295 \mathrm{mOsm}$ with sucrose. All recordings were amplified by an Axoclamp 700A amplifier (Molecular Devices), digitized at $10 \mathrm{kHz}$, and collected using custom software written in IGOR Pro (Wavemetrics). Series resistance was measured at the beginning of every sweep and maintained below $20 \mathrm{M} \Omega$ for all cells reported here. In voltage-clamp recordings, series resistance was compensated up to $75 \%$ and recordings were adjusted post hoc for the measured junction potential of $-11 \mathrm{mV}$. In current-clamp recordings, the resting membrane potential at the beginning of each sweep was set to $-70 \mathrm{mV}$ with DC current injection to prevent substantial inactivation of voltage-gated currents. Cells were excluded if their input resistance, resting membrane potential, or the access resistance changed by $>20 \%$ during a recording.

Electrophysiology analysis. Analyses of current- and voltage-clamp recordings were conducted off-line using custom IGOR Pro software. ISI ratio was measured as the second/last ISI in a $1 \mathrm{~s}$ spike train and was in some cases normalized to the maximum ISI in that train to account for differences in absolute firing rate. Only current injections within the linear region of each cell's FI curve (typically $5-25 \mathrm{~Hz}$ ) were considered. Resting input resistance was measured in current clamp with a $400 \mathrm{~ms}$ 25-50 pA hyperpolarizing current pulse delivered before every sweep and in voltage clamp with a $400 \mathrm{~ms} 5 \mathrm{mV}$ hyperpolarizing step, and resting membrane potential was measured at the beginning of recording and approximately every $10 \mathrm{~min}$ thereafter. Spike width was measured as the width of the action potential at half-height. Toxin-sensitive currents were obtained by subtraction, and their amplitude was measured at $200 \mathrm{~ms}$ after stimulus onset.

Morphological/anatomical analysis. Slices containing recorded cells were fixed from 2 to $14 \mathrm{~d}$ in cold $\left(4^{\circ} \mathrm{C}\right)$ buffered $4 \%$ paraformaldehyde. Biocytin was visualized by $1 \mathrm{~h}$ incubation with 1:500 AvidinD-TxRed or AvidinD-Fluorescein (Vector Laboratories) in $0.5 \%$ Triton X-100 after permeabilizing the membrane with $1 \%$ Triton X-100 for $45 \mathrm{~min}$ and rinsing 3 times for 10 min each in PBS. Stained cells were examined on a dissecting microscope equipped with epifluorescence and their somal locations recorded with respect to regional boundaries, and were imaged on a confocal microscope with a $63 \times$ objective to confirm the presence of YFP or retrograde label, and in some cases to perform morphometric measurements described previously (Hattox and Nelson 2007).

Histology. In preliminary experiments to assess the overlap between YFPH and PT populations, fluorescent microspheres (Lumafluor) were deposited via pressure injection in the pyramidal decussation of p23-p28 Thyl-YFPH mice. Surgical procedures were as previously described (Hattox and Nelson 2007). Briefly, mice were anesthetized with ketamine/xylazine/acepromazine (70, 3.5, and $0.7 \mathrm{mg} / \mathrm{kg}$ ), mounted on a stereotaxic frame, and the pons just ventral to the cerebellum was exposed by retracting the neck muscles. Glass micropipettes loaded with rhodamine microspheres and broken to a tip diameter of 30-50 $\mu$ m were lowered through the pons to the pyramidal tract. Forty-eight to sixty-two hours after tracer injection, mice were anesthetized and their brains fixed overnight in cold $\left(4^{\circ} \mathrm{C}\right)$ buffered $4 \%$ paraformaldehyde. $50 \mu \mathrm{m}$ coronal slices containing $\mathrm{M} 1$ and $\mathrm{S} 1$ were cut on a vibratome and imaged with a $50 \times$ objective on a confocal microscope. M1 and S1 were distinguished by the presence of a thicker layer 5 in M1. Cells were considered to be double labeled if the somal volume identified in the YFP signal subsumed the volume containing the microspheres. The resulting degree of overlap is likely to be an underestimate since not all axons exposed to the retrograde tracer will pick up and transport it.

Immunocytochemistry. Thy1-YFPH mice (p25-p29) were deeply anesthetized with ketamine/xylazine/acepromazine $(70,3.5$, and $0.7 \mathrm{mg} / \mathrm{kg}$ ), perfused with cold PBS followed by $4 \%$ paraformaldehyde (PFA), and their brains were cryoprotected in $4^{\circ} \mathrm{C}$ PFA containing $30 \%$ sucrose. Sagittal sections containing M1 and S1 were then cut at $15 \mu \mathrm{m}$ on a cryostat and stored at $4^{\circ} \mathrm{C}$ before staining. Slices were washed in PBS, blocked with $10 \%$ goat serum in $0.3 \%$ Triton X-100, incubated with monoclonal mouse IgG antibodies (NeuroMAB) against Kv1.1 (1:1000), Kv1.2 (1:75), Kv1.3 (1:150), or Kv1.5 (1:1000) overnight at $4^{\circ} \mathrm{C}$, washed again with PBS and $0.1 \%$ Triton X-100, incubated for $1-2 \mathrm{~h}$ in Cascade Blue goat anti-mouse (1:500; Invitrogen), and washed once more with PBS before mounting with fluoromount (EMS) and coverslipping. Antibody dilutions were determined by staining sections with a range of concentrations (typically $1: 1000$ to $1: 10$ ) and choosing the lowest dilution of each antibody that reliably stained cortical neuropil and somata. The specificity of each antibody has been previously established through the use of preadsorption with blocking peptide, and the absence of crossreactivity with other Kv1 subunits has been established in heterologous expression systems (Rhodes et al., 1995, 1997; Bekele-Arcuri et al., 1996; Rasband et al., 1998). Image stacks were acquired with a $100 \times$ objective on a confocal microscope at a z-step of $0.5 \mu \mathrm{m}$. Cell-type-specific Kv1 subunit expression was quantified in ImageJ by averaging the immunosignal subsumed by YFPH somata, and comparisons were made between M1 and S1 neurons imaged with equivalent laser power, gain, and pinhole settings in the same cryosection to minimize intersection differences in staining intensity. Identical results were obtained when we normalized the immunosignal subsumed by YFPH somata to nearby regions of background staining (i.e., regions devoid of brightly stained cellular processes) in the same FOV.

$q P C R$. Methods for tissue preparation and cell sorting were the same as described by Sugino et al. (2006). Briefly, $400 \mu \mathrm{m}$ coronal slices were cut on a vibratome, incubated for $90 \mathrm{~min}$ in protease solution $(1 \mathrm{mg} / \mathrm{ml}$ Pronase E; Sigma-Aldrich), and M1 and S1 were dissected from the slices under a dissecting microscope equipped with epifluorescence. Microdissected tissue was triturated in artificial CSF (ACSF) containing $1 \%$ fetal bovine serum with a series of three Pasteur pipettes of decreasing tip diameter, and the resulting cell suspension was diluted $200 \times$ with ACSF and deposited over a $100 \mathrm{~mm}$ Petri dish with Sylgard (Dow Corning) substratum. Under visual control on a fluorescence dissecting microscope, yellow fluorescent protein (YFP) expressing cells were aspirated using a mouth pipette system, and were subjected to three successive transfers into clean $35 \mathrm{~mm}$ Petri dishes containing fresh ACSF. These transfers substantially improved sample purity. Samples (60-80 cells) were then lysed in XB lysis buffer (Picopure Kit, Arcturus), incubated for 
$30 \mathrm{~min}$ at $42^{\circ} \mathrm{C}$ and then stored at $-20^{\circ} \mathrm{C}$ until further processing (which took place within 2 weeks). mRNA samples were then reverse transcribed, amplified by one round of in vitro transcription (MEGAscript Kit; Ambion), and reverse transcribed again and used as input cDNA for quantitative real time PCR on a Rotor-Gene 3000 (Corbett Research). The following primers were used in the PCRs: kcnal (forward primer: 5'-ACGGTGACATGTACCCTGTGACAA-3', reverse primer: 5'-ACTAACATGGAGCAACTGAGCCTG-3'), kcna2 (forward primer: 5' -AACCATTGCCTTACCAGTCCCTGT-3', reverse primer: 5'-GGGATCTTTGGACAGCTTGTCACT-3'), $k c n a 3$ (forward primer: 5'-CAGCCACTTGCACCACGAACACTA-3').

Statistics. Statistical differences between groups were assessed using unpaired 2-tailed Student's $t$ tests, while the statistical significance of within-cell comparisons was assessed with paired 2-tailed Student's $t$ tests. The Kolmogorov-Smirnov test was used to compare the anatomical distributions of YFPH and retrogradely labeled PT cells.

\section{Results}

We asked whether differences in intrinsic membrane properties contribute to differences between cortical regions by comparing the properties of pyramidal-tract $(\mathrm{PT})$ projecting layer 5 pyramidal cells in primary motor cortex (M1) to those in primary somatosensory cortex (S1) using an acute slice preparation from young adult (p23-p30) mice of the Thy1-YFPH transgenic line (Feng et al., 2000). Mice carrying the Thy1-YFPH transgene express yellow fluorescent protein (YFP) in a subset $(\sim 25 \%)$ of thick-tufted layer 5 cortical pyramidal cells that we have previously shown to have homogeneous electrophysiological and transcriptional properties distinct from other pyramidal cell populations (Sugino et al., 2006). In M1 and S1, YFPH+ cells can be retrogradely labeled from the $\mathrm{PT}$ and neighboring pontine nuclei (Fig. 1), indicating that they contribute to the corticospinal and corticobulbar projections and are anatomically congruent populations. Neither the overlap between YFPH and PT populations nor their laminar distributions were significantly different in M1 and S1 (Fig. 1, bottom panels). Several morphological parameters of YFPH cells did not differ between M1 and S1, including apical dendrite length $(789.5 \pm 2.5 \mu \mathrm{m}$ in $\mathrm{M} 1$ vs $798.5 \pm 8.2 \mu \mathrm{m}$ in $\mathrm{S} 1$, $p=0.32)$, soma area $\left(946.4 \pm 33.7 \mu \mathrm{m}^{2}\right.$ in $\mathrm{M} 1$ vs $881.8 \pm 60.3$ $\mu \mathrm{m}^{2}$ in $\left.\mathrm{S} 1, p=0.36\right)$, number of apical branches $(3 \pm 0.2$ in $\mathrm{M} 1$ vs $3.1 \pm 0.3$ in $S 1, p=0.77)$, and apical tuft width $(180.2 \pm 9.4$ $\mu \mathrm{m}$ in $\mathrm{M} 1$ vs $184.8 \pm 3.2 \mu \mathrm{m}$ in $\mathrm{S} 1, p=0.65)$. The apical dendrite width measured $5 \mu \mathrm{m}$ from the soma was slightly greater in S1 $(5.1 \pm 0.3 \mu \mathrm{m})$ than $\mathrm{M} 1(4.01 \pm 0.1 \mu \mathrm{m}, p<0.05)$. The equivalent anatomy and morphology of YFPH/PT cells in M1 and S1, and the relative ease with which they can be reliably targeted and isolated for electrophysiological and molecular assays, makes them an ideal point of comparison between cortical regions. This is particularly true of YFPH/PT cells in M1 and S1, since these two cortical regions differ markedly in cytoarchitecture and function yet both project to the brainstem and spinal cord and these projections arise from YFPH/PT cells.

\section{YFPH/PT firing type is region specific}

We first compared the firing types of YFPH/PT cells in M1 to those in S1. YFPH/PT cells in S1 always (16 of 16) discharged nonadapting trains of action potentials, often with an initial doublet (Fig. 2A), similar to what we and others have observed in thick-tufted layer 5 cells in sensory and prefrontal cortices (Bekkers and Delaney, 2001; Morishima and Kawaguchi, 2006; Sugino et al., 2006; Wang et al., 2006; Hattox and Nelson, 2007). Surprisingly, YFPH/PT cells in M1 exhibited a delayed first spike followed by pronounced spike-frequency acceleration: the interspike interval (ISI) decreased substantially over the course of $1 \mathrm{~s}$
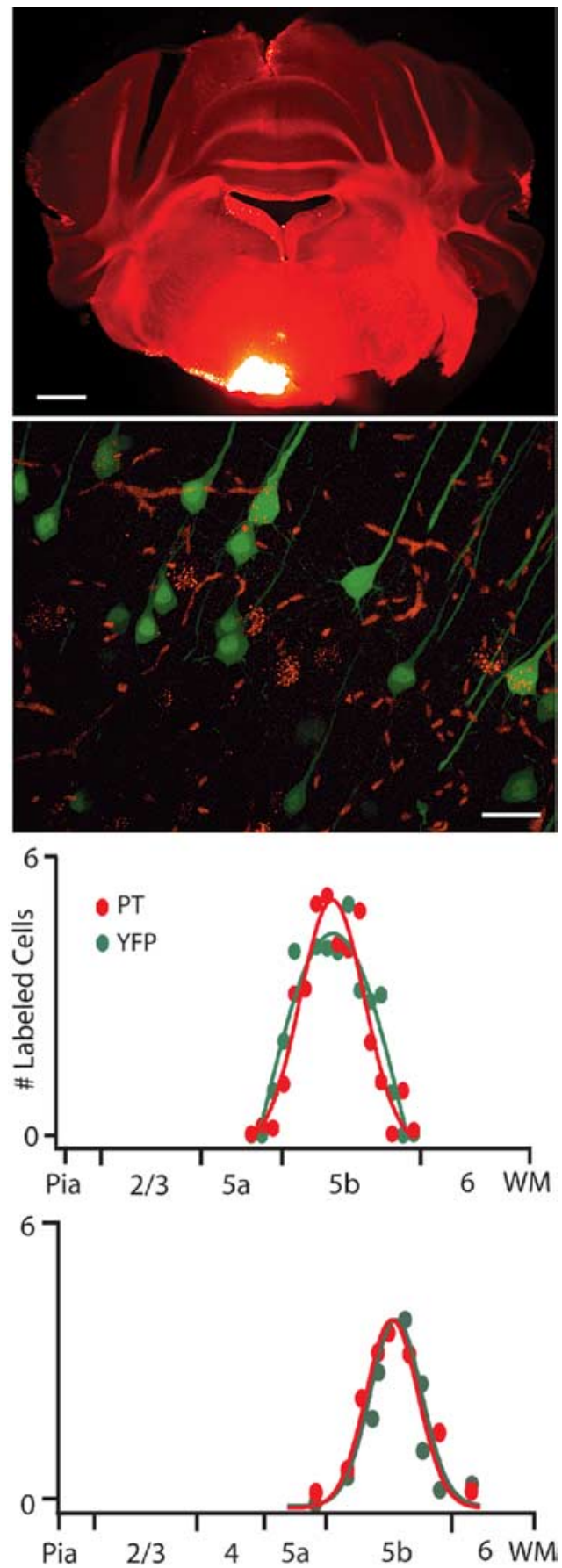

Figure 1. YFPH cells project through the pyramidal tract (PT). Fluorescent microspheres deposited in the pyramidal tract (top) are retrogradely transported to the somata of YFPexpressing layer 5 pyramidal cells (middle). Within the area most densely labeled by microspheres, $42.9 \pm 9 \%$ of YFP cells $(n=92)$ and $53.6 \pm 11 \%$ of retrogradely labeled cells $(n=$ 87) are double labeled ( $n=4$ FOV from 2 animals). The laminar distributions in both M1 and S1 of retrogradely labeled and YFP cells overlap, are largely confined to layer 5b, and are not statistically different (bottom). Scale bars indicate $1 \mathrm{~mm}$ (top) and $25 \mu \mathrm{m}$ (middle).

in response to current injections within the linear region of each cell's FI curve (Fig. 2A). We quantified the degree of acceleration as the ratio of the second to last ISI in a spike train, thus yielding values $>1$ for accelerating spike trains and $<1$ for adapting trains. Comparing the second rather than the first to last ISI more accurately reflects the lack of adaptation in S1 cells following their initial doublet. The ISI ratio was significantly greater in M1 (1.48) 
A


$20 \mathrm{mV}$

$7.5 \mathrm{mV} L$

Figure 2. The intrinsic membrane properties and firing types of PT-projecting layer 5 pyramidal cells are regionally distinct. $\boldsymbol{A}$, Whereas PT-projecting cells in S1 produce nonadapting trains of action potentials in response to current injection, their counterparts in M1 exhibit a delayed first spike and subsequent spike-frequency acceleration. Subthreshold current injection produces a depolarizing voltage ramp in M1 but not S1. B, Population interspike interval (ISI) curves from M1 (dark gray, $n=39$ ) and S1 (light gray, $n=16$ ). The ratio of the second to last ISI, a measure of spike-frequency adaptation, is statistically different between regions $(p<0.01)$. Envelopes indicate SEM. C, Somal locations of reconstructed accelerating (dark circles) and nonadapting cells (light circles) with respect to cortical regional boundaries. Accelerating cells are found exclusively in M1 and on the M1/M2 border.

seconds. Whole-cell conductance measurements made in voltage clamp in the presence of $2 \mu \mathrm{M}$ TTX revealed a voltagedependent decrease in conductance over time (supplemental Fig. S2, available at www.jneurosci.org as supplemental material) in M1 but not $\mathrm{S} 1$, indicating the presence of a region-specific slowly inactivating outward current. The temporal characteristics of the conductance decrease observed in M1 YFPH/PT cells, namely inactivation over hundreds of milliseconds, and the prominently delayed first spike in M1 YFPH/PT cells, are consistent with the properties of $I_{\mathrm{D}}$, a well characterized slowly inactivating potassium current thought to be mediated by $\mathrm{Kv} 1 /$ shaker channels and sensitive to low concentrations of 4-AP and dendrotoxin (Storm, 1988; Wu and Barish, 1992; Brew and Forsythe, 1995; Hopkins, 1998; Bekkers and Delaney, 2001; Brew et al., 2003; Shen et al., 2004; Guan et al., 2006, 2007). Bath application of either $100 \mu \mathrm{M} 4$-AP (data not shown) or 50-100 nM dendrotoxin-I (DTX) blocked an $I_{\mathrm{D}}$-like current in M1 YFPH/PT cells (9 of 9 cells) but not those in S1 (0 of 5). This current activated above $-55 \mathrm{mV}$ and contained both rapidly $(\tau=32.9 \pm 5.1 \mathrm{~ms}$ at -30 $\mathrm{mV})$ and slowly $(\tau=970.2 \pm 212.7 \mathrm{~ms}$ at $-30 \mathrm{mV}$ ) inactivating components (Fig. 3). At membrane voltages traversed by ISIs in current clamp $(-40 \mathrm{mV})$, rapid inacti-

than in S1 $(0.98, p<0.01)$. Additionally, subthreshold current injection elicited a depolarizing voltage ramp in M1 but not $\mathrm{S} 1$ YFPH/PT cells (Fig. $2 A$; ramp is quantified in supplemental Fig. S1, available at www.jneurosci.org as supplemental material). A delayed first spike, acceleration, and subthreshold voltage ramp were invariably observed in both YFPH (39 of 39) and retrogradely labeled PT-projecting (16 of 16) cells in M1, further demonstrating the PT and YFPH populations overlap and that the intrinsic membrane properties of a discrete cell type differ across functionally distinct cortical regions (Fig. $2 B, C$ ). Both doublelabeled cells and cells labeled with either retrograde label or YFP always expressed these properties in M1, and we never observed acceleration in labeled cells in S1. We also found YFPH cells in cingulate $(n=9)$ and secondary visual cortex $(n=5)$ to be nonadapting, like YFPH/PT cells in S1 (data not shown). Although acceleration has been previously observed in a subset of layer 5 pyramidal cells in cat [Spain et al. (1991b), their Fig. $1 B$ ] and adult rat (La Camera et al., 2006) sensorimotor cortex, this is the first demonstration that a cell-type-specific firing type varies systematically between neocortical regions.

\section{An $I_{D}$-like current mediates spike-frequency acceleration in $\mathrm{M} 1$}

The depolarizing current ramp evoked by subthreshold current injection in M1 but not S1 (Fig. 2A) suggests that the biophysical mechanisms underlying acceleration do not require spiking, and are instead due to either the slow activation of an inward current or the slow inactivation of an outward current that in/activates at subthreshold membrane potentials and over hundreds of milli- vation occurred with $\tau=59.8 \pm 8.4 \mathrm{~ms}$ and slow inactivation occurred with $\tau=997.9 \pm 182.2 \mathrm{~ms}$. DTX also largely abolished the whole-cell conductance decrease observed in M1 (supplemental Fig. S2, available at www.jneurosci.org as supplemental material). Subtracting currents evoked by the same voltage protocol before and after 20 min of ACSF (without DTX) perfusion revealed a small $(\sim 30 \mathrm{pA})$ voltage-dependent inward current, thus ruling out the possibility that the DTX-sensitive current is due to rundown (supplemental Fig. S3, available at www. jneurosci.org as supplemental material). These results support the hypothesis that a DTX-sensitive slowly inactivating potassium current present in M1 and absent in S1 confer a regionspecific firing type on a discrete class of layer 5 pyramidal cells. We directly tested this hypothesis by measuring the degree of spike-frequency acceleration in M1 YFPH/PT cells before and after bath application of DTX (Fig. 4). 100 nM DTX significantly reduced the ISI ratio in M1 YFPH/PT cells from 1.57 to $1.08(n=$ $8, p<0.01)$ and dramatically reduced the characteristic delay to first spike without significantly altering resting $V_{\mathrm{m}}(-69.3 \mathrm{mV}$ in ACSF and $-68.1 \mathrm{mV}$ in DTX, $p=0.57), R_{\mathrm{In}}(97.3 \mathrm{M} \Omega$ in ACSF and 101.8 $\mathrm{M} \Omega$ in DTX, $p=0.43$ ), or action potential half-width (1.01 $\mathrm{ms}$ in ACSF and $0.99 \mathrm{~ms}$ in DTX, $p=0.61$ ). DTX also increased the intrinsic excitability of M1 YFPH/PT cells by decreasing rheobase from $367 \mathrm{pA}$ to $271 \mathrm{pA}(p<0.01)$ and action potential voltage threshold from $-46.02 \mathrm{mV}$ to $-48.6 \mathrm{mV}(p<$ 0.01 ). Although this increase in excitability produced higher firing rates in response to the same current injection after DTX application (Fig. 4A, leftmost and rightmost traces), spikefrequency acceleration was absent at all firing rates in the pres- 
ence of DTX (Fig. 4D) and its loss was therefore not due to firing rate saturation.

Kv1.2 and Kv1.3 contribute to distinct components of spike-frequency acceleration

$I_{\mathrm{D}}$-like slowly inactivating potassium currents are thought to be mediated by heterotetramers containing Kv1.1-6 $\alpha$ subunits, and their kinetics are largely determined by subunit stoichiometry and modulation by $\operatorname{Kv} \beta$ subunits (Stühmer et al., 1989; Isacoff et al., 1990; Jan and Jan, 1992; Rettig et al., 1994; Sewing et al., 1996). DTX blocks channels containing Kv1.1, Kv1.2, or Kv1.6 subunits. The presence of Kv1.2 and Kv1.3 subunits are particularly associated with slow inactivation when expressed in oocytes (Po et al., 1993; Hopkins et al., 1994; Hopkins, 1998) and heterologous expression systems (Ruppersberg et al., 1990; Coetzee et al., 1999), and endogenously in neurons in slices (Dodson et al., 2002; Shen et al., 2004; Guan et al., 2006, 2007). We therefore sought to determine whether Kv1.2- and Kv1.3-containing channels contributed to the $I_{\mathrm{D}}$-like current and unique accelerating firing type observed in M1 YFPH/PT cells. Bath application of the Kv1.3-specific (Garcia-Calvo et al., 1993) toxin r-margatoxin (MTX, $10 \mathrm{nM}$ ) in M1 YFPH/PT cells blocked a rapidly activating current with a rapidly inactivating transient component ( $\tau=25.2 \pm 6.1 \mathrm{~ms}, n=6$ ), no further inactivation over $1 \mathrm{~s}$, and a voltage dependence similar to the DTX-sensitive current (Fig. 5A). Conversely, application of the Kv1.2-specific (Werkman et al., 1993) toxin tityustoxin (TiTX, $25 \mathrm{nM}$ ) revealed the presence of a slowly inactivating $(\tau=802.5 \pm 98 \mathrm{~ms}, n=4)$ current lacking a transient component that also shared the voltage dependence of the DTX-sensitive current (Fig. 5A,B). Together, these results suggest that separate populations of channels containing Kv1.2 and Kv1.3 contribute differentially to the kinetics of the DTX-sensitive current: channels with Kv1.2 but not Kv1.3 mediate slow inactivation whereas those containing Kv1.3 but not Kv1.2 contribute a rapidly decaying transient. An important prediction of this model is that blocking the Kv1.3-mediated transient current with MTX should diminish the characteristic delayed spiking in M1 YFPH/PT cells but leave acceleration unaffected, while TiTX application should produce the opposite effect. This was indeed the case (Fig. $5 C$ ): spike latency was reduced in 8 of 8 cells by $47.6 \%$ in the presence of 10 nM MTX but was not significantly altered by $25 \mathrm{nM}$ TiTX $(n=8)$, while the ISI ratio in the same cells was unaffected by MTX but was significantly decreased by TiTX (from 1.63 in ACSF to 1.24 in TiTX, $p<$ 0.01 ). These results provide strong evidence that channels containing Kv1.2 and Kv1.3 mediate separate components of the accelerating firing type observed in M1 YFPH/PT cells.

\section{Cell-type-specific Kv1 subunit expression is regionally distinct}

If region- and cell-type-specific differences in Kv1 subunit expression are critical determinants of the distinct firing type found in M1 YFPH/PT layer 5 pyramidal cells, there should be measur- able differences in Kv1 protein expression and/or kcna mRNA expression between YFPH/PT cells in M1 and those in S1. We immunolabeled Kv1.1, Kv1.2, Kv1.3, and Kv1.5 subunits in cryosections containing both M1 and S1 from Thy1-YFPH mice to examine regional differences in Kv1 subunit expression, and used cell-type-specific quantitative real-time PCR ( $\mathrm{PPCR}$ ) to assay mRNA levels. All four antibodies labeled somata of YFPH and non-YFPH cells in both M1 and S1 (Fig. 6A), consistent with previous reports demonstrating the presence of these subunits in a number of cortical cell types and regions (Wang et al., 1994; Veh et al., 1995; Porter et al., 1998; Guan et al., 2006). Kv1 subunits are also found in axon terminals where they regulate synaptic transmission (Wang et al., 1994), and in the axon initial segments of cortical pyramidal cells (Kole et al., 2007; Shu et al., 2007). Restricting our analysis to immunolabeled regions coextensive with the YFP signal allowed us to examine Kv1 expression exclusively in YFPH/PT cells. The amount of immunolabel restricted to YFPlabeled somata was reliably and significantly greater in M1 than in S1 for all four subunits (Fig. $6 B)(n=2$ cryosections, $>3$ FOV each). Interestingly, kcnal-3 transcripts were not significantly enriched in YFPH neurons sorted from M1 compared with S1 (Fig. $6 B$ ), suggesting that region-specific Kv1 subunit expression may be mediated by a posttranscriptional mechanism.

\section{Expression of a DTX-sensitive current endows M1 YFPH/PT neurons with intrinsic short-term memory}

The initial characterization of $I_{\mathrm{D}}$ by Storm (1988) in hippocampal pyramidal cells demonstrated that its slow inactivation and voltage-dependent deinactivation bestow a form of cellular short-term memory on cells that express it, such that prolonged depolarization or rapidly delivered depolarizing stimuli alter cellular excitability and integration over hundreds of milliseconds. 
A
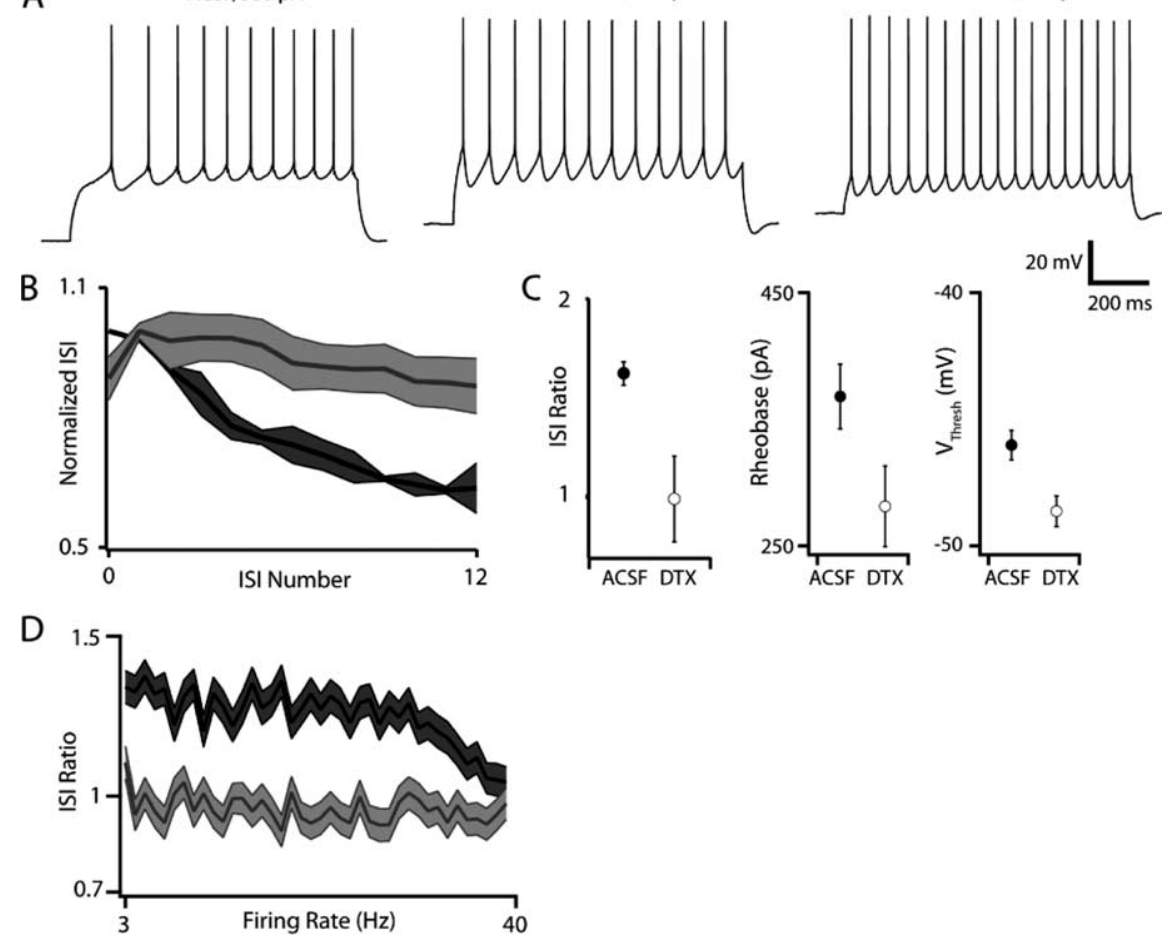

Figure 4. Spike-frequency acceleration is DTX sensitive. Application of $100 \mathrm{~nm}$ DTX-I profoundly and significantly ( $p<0.01$, $n=8$ ) attenuates spike-frequency acceleration in M1 PT-projecting cells. $A$, Voltage traces elicited by $380 \mathrm{pA}$ current injection in the absence and presence of $100 \mathrm{~nm}$ DTX-I (leftmost and rightmost traces), and by a $280 \mathrm{pA}$ injection in DTX that evokes a firing rate equivalent to the 380 pA injection in ACSF. B, Population ISI curves ACSF (dark gray) and DTX (light gray). C, Effects of DTX on ISI ratio, rheobase, and action potential voltage threshold. DTX abolished acceleration and increased excitability. $\boldsymbol{D}$, The relationship between ISI ratio and firing rate before and after DTX application, indicating that the effect of DTX on acceleration occurs at all firing rates tested.
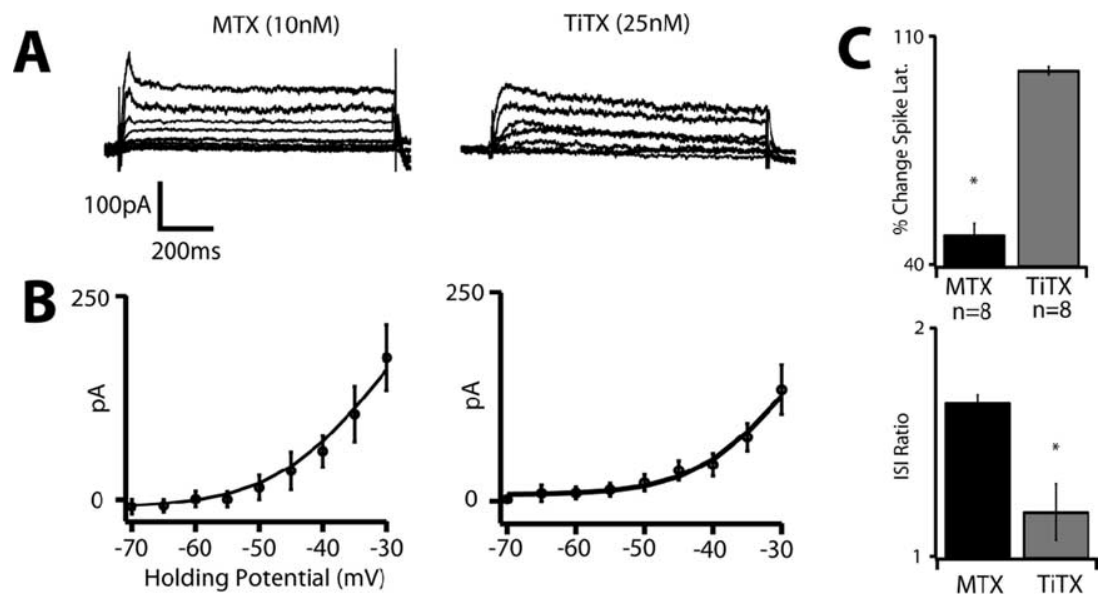

Figure 5. MTX-and TiTX-sensitive currents contribute to distinct features of M1 cells' firing type. $A, M T X$ ( $10 \mathrm{nM}$ )- and TiTX (25 nM)- sensitive currents in M1 PT-projecting cells. Whole-cell current was measured in voltage clamp by stepping to holding potentials between -70 and $-30 \mathrm{mV}$ from $-80 \mathrm{mV}$, and the drug-sensitive currents were obtained by subtraction. The MTX-sensitive current includes a transient component that decays rapidly, with no further inactivation, whereas the TiTXsensitive current decays slowly. $\boldsymbol{B}$, Population IV curves for the MTX-sensitive current (left, $n=9$ ) and TiTX-sensitive current (right, $n=10)$. Error bars indicate SEM. C, MTX but not TiTX significantly $(p<0.01)$ decreases the latency to first spike (top graph), whereas TiTX but not MTX significantly $(p<0.01)$ attenuates spike-frequency acceleration (bottom graph). Error bars indicate SEM.

Similar properties have been observed in $I_{\mathrm{D}}$-expressing neocortical interneurons (Porter et al., 1998) and when slowly inactivating outward currents with the same kinetics and voltage dependence as $I_{\mathrm{D}}$ are introduced into lobster stomatogastric neurons

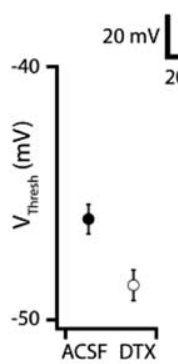

via dynamic clamp (Turrigiano et al., 1996). We therefore asked whether the presence of an $I_{\mathrm{D}}$-like current in $\mathrm{M} 1$ YFPH/PT cells endowed them with a form of intrinsic short-term memory by injecting a series of $1 \mathrm{~s}$ suprathreshold stimuli separated by interstimulus intervals ranging from 50 to $1000 \mathrm{~ms}$, and compared the ISI ratio of the response to each stimulus in a train (Fig. 7). Although the first stimulus in a train always evoked an accelerating firing pattern preceded by a delayed first spike, stimuli separated by $<250 \mathrm{~ms}$ produced consecutively less acceleration. In fact, the fifth stimulus in a train with $50 \mathrm{~ms}$ interstimulus intervals evoked a completely nonadapting spike train reminiscent of those observed in S1 YFPH/PT cells [Fig. $7 B$ (right panel), $D$ (bottom right); compare with Fig. $2 B$ ]. Importantly, the time course of this effect parallels the deinactivation kinetics of the DTX-sensitive current in these cells (supplemental Fig. S4, available at www.jneurosci.org as supplemental material), indicating that an important component of the dynamic integrative properties of M1 YFPH/PT pyramidal cells are primarily mediated by the presence and deinactivation kinetics of an $I_{\mathrm{D}}$-like current.

\section{Discussion}

We tested whether the intrinsic membrane properties of an identified and discrete cell type vary between neighboring but functionally distinct neocortical regions by directly comparing YFPH/PT layer 5 pyramidal cells in primary motor and primary somatosensory cortices. Our results reveal the presence of an "accelerating" firing type specific to YFPH/PT cells in M1 that is mediated by region- and cell-type-specific Kv1 subunit expression, and demonstrate for the first time that the intrinsic membrane properties of a discrete neocortical cell type can be region specific.

Importantly, we find that accelerating YFPH/PT cells are restricted to motor cortex: the same cells are uniformly nonadapting despite being anatomically identical in somatosensory and cingulate cortices. Unlike morphological differences between cortical areas, which tend to follow a clear rostrocaudal gradient (Elston, 2000, 2002; Benavides-Piccione et al., 2002; Elston and DeFelipe, 2002), the presence of accelerating cells in motor cortex but not in immediately anterior or posterior cortical areas indicates that this property does not vary in a gradient across cortex but instead reflects a unique specialization that is likely important for the functionality of motor cortex.

Spike-frequency acceleration has been previously observed in 


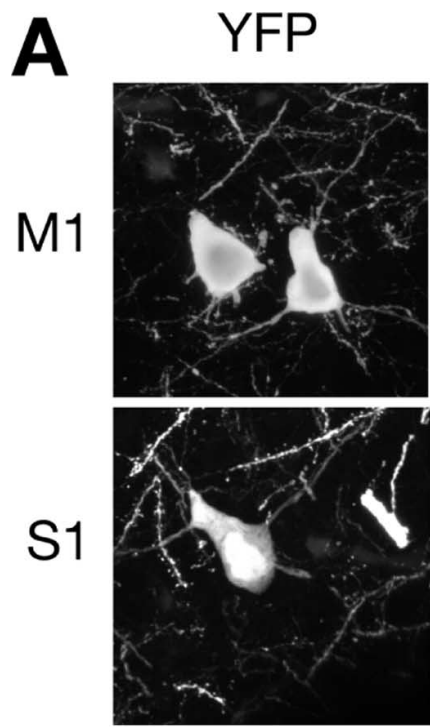

anti-Kv1.1
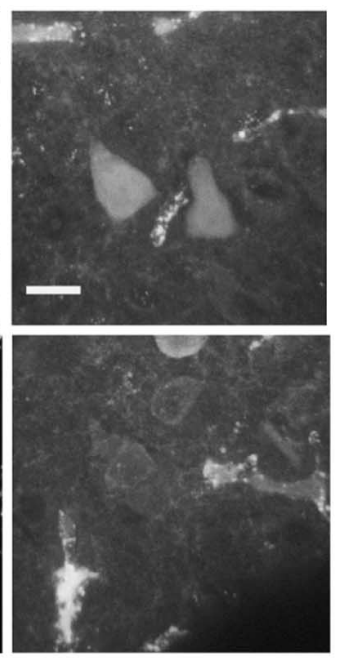

YFP

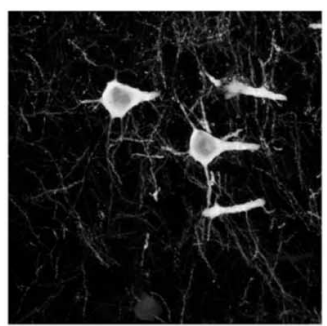

M1

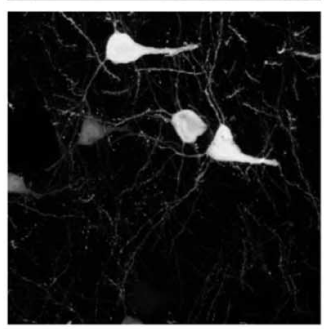

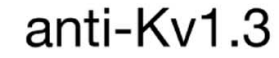
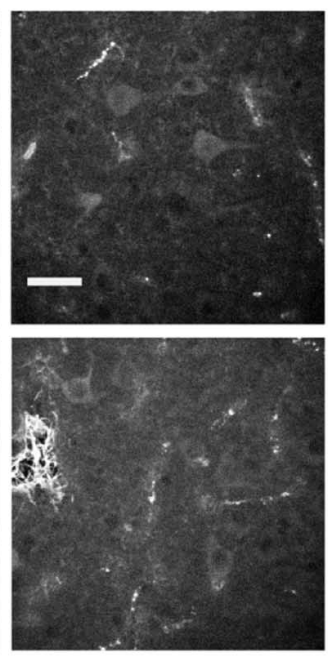

YFP
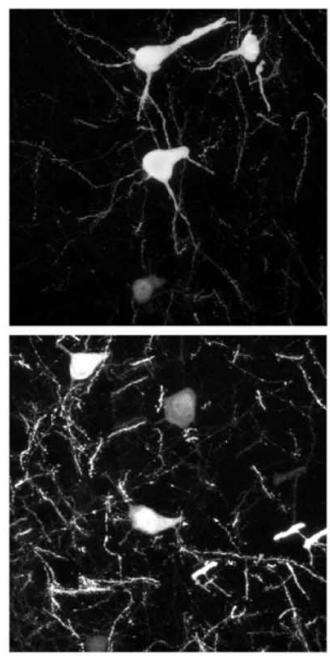

YFP
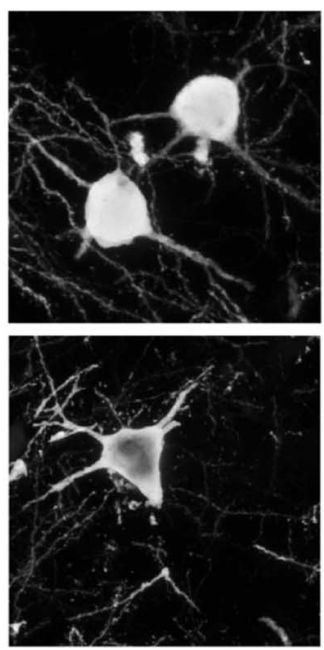

anti-Kv1.2

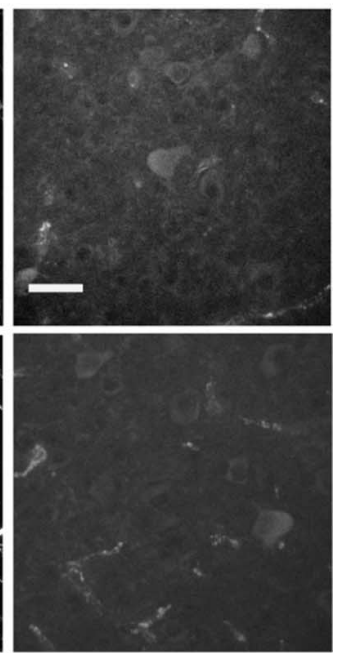

anti-Kv1.5
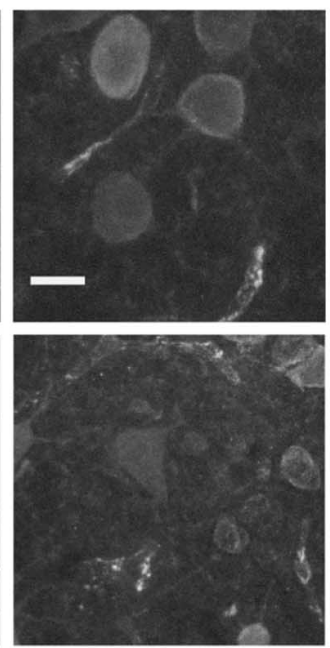

B
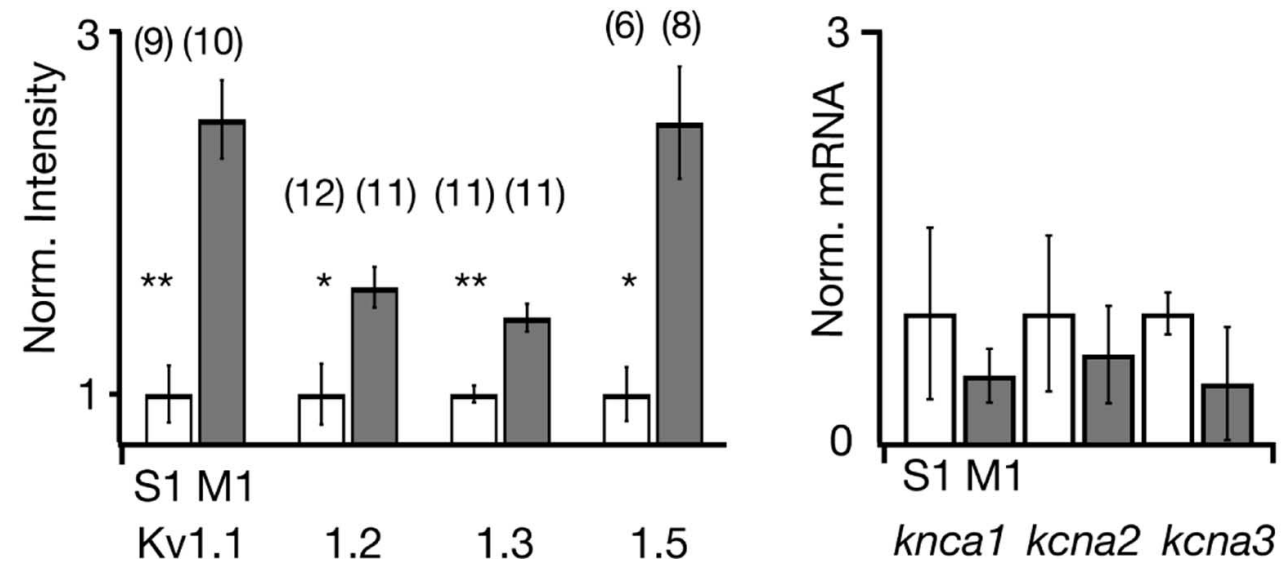

knca1 kcna2 kcna3

Figure 6. Regional cell-type-specific differences in Kv1 subunit expression parallel differences in firing type. M1 YFPH/PT pyramidal cells express significantly more Kv1 protein than their counterparts in S1. A, Confocal z-projections of YFPH layer 5 pyramidal cells (left columns) and Kv1 immunocytochemistry (ICC, right columns) in the same field of view (FOV). Scale bars: $15 \mu \mathrm{m}$ for Kv1.1 and Kv1.5, and $25 \mu \mathrm{m}$ for Kv1.2 and Kv1.3. B, Expression of Kv1.1, Kv1.2, Kv1.3, and Kv1.5 in M1 and S1 YFPH pyramidal cells. Subunit expression was quantified (left graph) by averaging the Kv1 immunosignal subsumed by YFP-labeled somata throughout the imaged volume and normalizing to $\mathrm{S1}$ expression. Expression of all three subunits is significantly higher in M1 than in $\mathrm{S} 1$ ( $p<$ 0.001 for Kv1.1 and Kv1.3, and $p<0.01$ for Kv1.2 and Kv1.5). Sample sizes for each condition are above each bar. qPCR quantification (right graph) of kcna1, kcna2, and kcna3 mRNA harvested from three samples of $60-80$ acutely dissociated YFPH cells from M1 and $\mathrm{S} 1$ reveals no significant regional differences, suggesting that region-specific Kv1 subunit expression is regulated posttranscriptionally. Bars represent average expression normalized to the 51 expression of each transcript. 

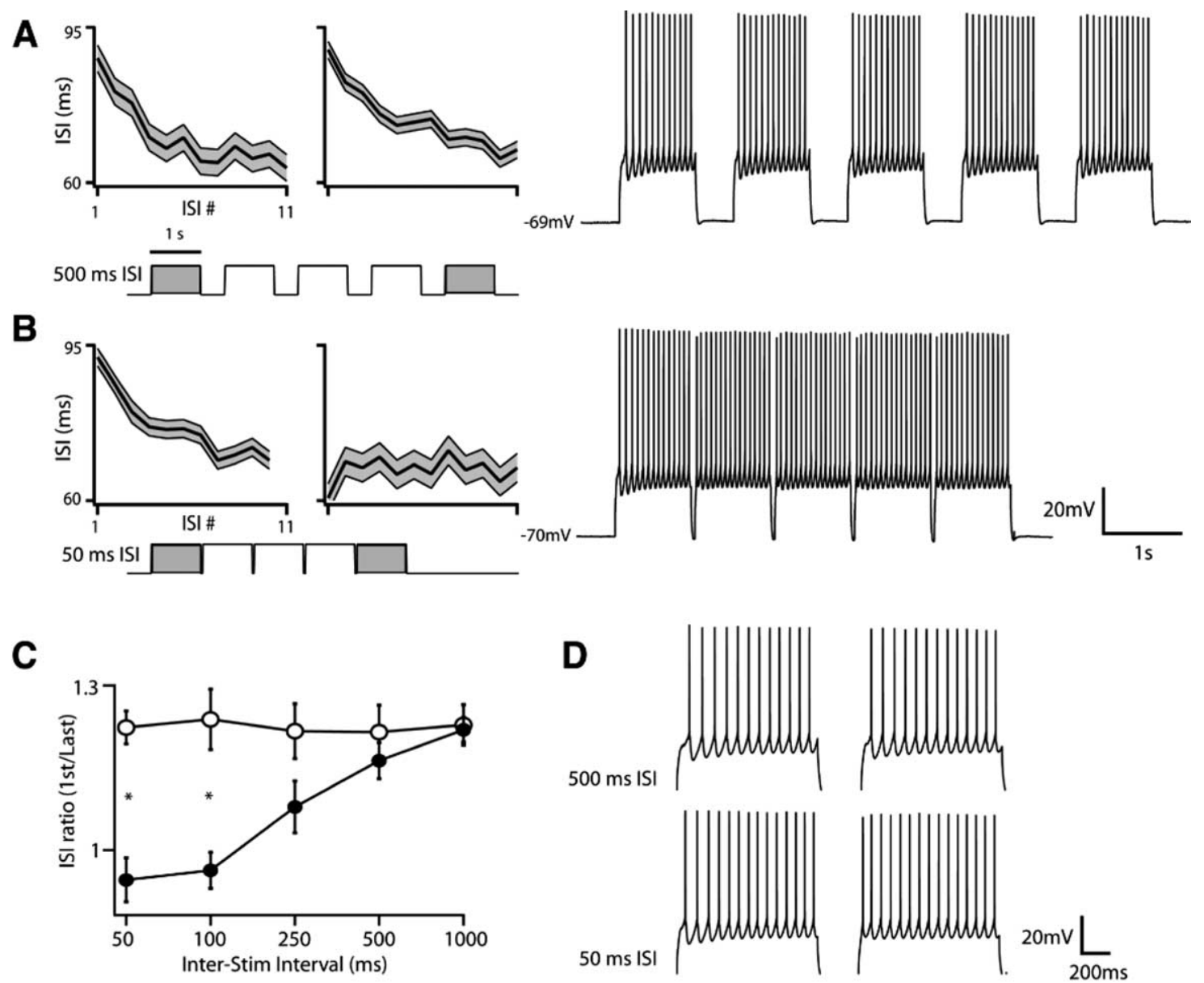

Figure 7. I I inactivation kinetics confer a form of intrinsic short-term memory on M1 PT-projecting layer 5 pyramidal cells. The presence and inactivation kinetics of a DTX-sensitive current in M1 PT-projecting cells renders their firing type sensitive to recent depolarization. Stimuli preceded by hyperpolarized epochs elicit accelerating spike trains whereas stimuli that arrive within $250 \mathrm{~ms}$ of a depolarizing stimulus elicit nonadapting spike trains. $A$, Interspike-interval (ISI) curves (left) computed from the first and fifth epochs of $1 \mathrm{~s}$ stimuli delivered $500 \mathrm{~ms}$ apart, and an example spike train (right) generated by the same stimulus. Note that cells discharge accelerating spike trains for both the first and last stimuli. $\boldsymbol{B}$, ISI curves and a spike train acquired from the same cells as in $\boldsymbol{A}$ but with stimuli separated by $50 \mathrm{~ms}$. Note that although the first stimulus elicits an accelerating spike train, the response to the fifth stimulus is nonadapting, and that the membrane potential returns to $-70 \mathrm{mV}$ between stimuli. C, Adaptation (expressed as the ratio of the second to last ISI) as a function of interstimulus interval. Open circles indicate the ISI ratio in response to the first stimulus and closed circles indicate responses to the fifth. Differences in spike-frequency acceleration between the first and last stimuli are statistically significant $(p<0.01, n=5)$ at interstimulus intervals shorter than $250 \mathrm{~ms}$, indicating that the firing type of PT-projecting pyramidal cells in M1 is highly sensitive to recent activity. D, Spiking responses to individual first and last stimuli at 500 ms (top) and $50 \mathrm{~ms}$ (bottom) ISI at an expanded time scale.

a handful of predominantly motor and premotor structures. Unlike YFPH/PT cells, which accelerate over the linear portion of their FI curve, neurons in the subthalamic nucleus accelerate only at high firing rates due to a combination of high-voltage activated calcium, persistent sodium, and calcium-dependent potassium currents (Bevan and Wilson, 1999; Wilson et al., 2004). In the dorsal horn, spike-frequency acceleration similar to that observed here is mediated by Kir3 channels linked to $\mathrm{GABA}_{\mathrm{B}}$ and metabotropic glutamate receptors (Derjean et al., 2003). In this system, modulation of acceleration rapidly switches the network between gating and amplifying modes. This suggests that spikefrequency acceleration may be crucially involved in generating certain circuit dynamics, and raises the intriguing possibility that cell types in different motor structures have evolved this property separately and express it by different means.

In the neocortex, spike-frequency acceleration has been occasionally reported in subpopulations of pyramidal cells from rodent (La Camera et al., 2006) and cat (Spain et al., 1991a,b) "sensorimotor" cortex, and in neocortical vasoactive intestinal peptide (VIP)-positive irregular-spiking interneurons (Porter et al., 1998), although ours is the first description of the mechanism and regional specificity of acceleration in identified cortical pyramidal cells. As in YFPH/PT cells, acceleration in neocortical VIP-positive interneurons is mediated by a DTX-sensitive current, albeit one with slower inactivation kinetics (Porter et al., 1998). Interestingly, Cheney and Fetz (1980) reported a population of PT-projecting neurons in monkey motor cortex that exhibited accelerating "warm up firing" during a motor task, suggesting that this firing property is present in vivo and is engaged during behavior.

Anions in the pipette solution can modulate intrinsic membrane properties (Schwindt et al., 1992; Zhang et al., 1994). Gluconate is known to inhibit the slow-afterhyperpolarization (sAHP) in hippocampal neurons, and methylsulfate reduces the postspike afterdepolarization (ADP) and increases $R_{\text {In }}$ (Kaczorowski et al., 2007). Many cell types exhibit less spike-frequency adaptation when dialyzed with gluconate, presumably due to inhibition of the SAHP and preservation of the ADP. Although layer 5 pyramids express relatively small sAHPs (Schwindt et al., 1988; Villalobos et al., 2004), it is possible that regional differences in currents sensitive to intracellular gluconate may contribute to regional differences in firing type measured with whole-cell patch 
clamp. However our toxin results, as well as earlier reports of accelerating "warm-up" firing obtained from layer 5 pyramidal cells with sharp electrodes that do not replace intracellular anions (Spain et al., 1991a,b) suggest that acceleration is not an artifact of gluconate dialysis.

Many cell types, including cortical pyramidal cells (Bekkers and Delaney, 2001; Guan et al., 2006, 2007; Kole et al., 2007; Shu et al., 2007), striatal medium spiny cells (Shen et al., 2004), and neurons in the auditory periphery and brainstem (Brew and Forsythe, 1995; Adamson et al., 2002; Dodson et al., 2002; Mo et al., 2002; Brew et al., 2003) are known to express potassium currents mediated by Kv1 channels. In some cases, and in agreement with our results, different Kv1 heteromers regulate different components of a neuron's firing type (Dodson et al., 2002). Foehring and colleagues have demonstrated that layer $2 / 3$ cortical pyramidal cells express a variety of Kv1 heteromers with distinct kinetics that regulate excitability and action potential width (Guan et al., 2006, 2007). In these cells, dendrotoxin increases excitability but leaves the firing type unaffected, which in concert with the results presented here indicates that even among cortical pyramidal cells the role of Kvl channels is cell type specific. Recently, combined somatic and axonal recordings from prefrontal and somatosensory neocortical pyramidal cells have provided compelling evidence that axonal Kv1 channels strongly influence both the action potential waveform and synaptic strength, and allow subthreshold somatic voltage changes to dynamically alter axonal action potential kinetics (Kole et al., 2007; Shu et al., 2007). Together with our finding that a Kv1-mediated slowly inactivating potassium current renders the firing type of layer 5 YFPH/PT cells sensitive to recent input, these results support the idea that Kv1 channels are crucial determinants of neocortical neuronal integrative properties. Since Kv1 current magnitude (Bowlby et al., 1997; Fadool and Levitan, 1998) and biophysical properties (Manganas and Trimmer, 2000; Finnegan et al., 2006) are subject to several known forms of rapid modulation, they are ideally suited to provide a means of adjusting neocortical dynamics on time scales of hundreds of milliseconds.

It remains possible that regional differences in subcellular Kv1 localization rather than absolute expression contribute to the regional difference in firing type. Dendritic Kv1 expression, for example, would produce smaller and distorted somatic currents due to dendritic filtering and the inability of a somatic voltage clamp to maintain voltage control over the dendrites of large cells. Our immunohistochemistry indicates, however, that Kv1 subunits are expressed in the same subcellular compartments in M1 and S1 (Fig. 6), and it is therefore unlikely that dramatic regional differences in Kv1 localization account for regionally restricted spike-frequency acceleration. Moreover, the somatic and perisomatic localization of Kv1 subunits in M1 and S1 renders them unlikely to escape the voltage clamp imposed by a somatic electrode and less subject to dendritic filtering (Williams and Mitchell, 2008).

Slowly inactivating $I_{\mathrm{D}}$-like potassium currents are present in a number of cell types throughout the mammalian brain and in many cases confer important functional properties on cells that express them. In the auditory system, $I_{\mathrm{D}}$ allows both peripheral (Adamson et al., 2002; Mo et al., 2002) and central neurons (Brew and Forsythe, 1995; Brew et al., 2003) to preserve a stimulus' temporal information by preventing tonic firing. Storm's initial characterization of $I_{\mathrm{D}}$ in hippocampal pyramidal cells emphasized the form of intrinsic short-term memory that results from its deinactivation kinetics (Storm, 1988), and we also observed this property. Because $I_{\mathrm{D}}$ is activated at depolarized membrane voltages, inactivates over hundreds of milliseconds, and only deinactivates if hyperpolarized for another several hundred milliseconds, it is tempting to speculate that its influence on M1 $\mathrm{YFPH} / \mathrm{PT}$ integrative properties will be most profound during transitions from the "down" state to the "up" state (Steriade et al. 1993; Cowan and Wilson, 1994; Sanchez-Vives and McCormick, 2000; Haider et al., 2006). Specifically, periods of sparse excitation or inhibition lasting longer than 500 ms would allow deinactivation of $I_{\mathrm{D}}$ and render YFPH/PT cells less responsive to transient stimuli but capable of amplifying sustained input over time, whereas more frequent bouts of sustained excitation would promote $I_{\mathrm{D}}$ inactivation, increase the excitability of YFPH/PT cells, and produce a more linear transformation of synaptic activity over time.

Spike-frequency adaptation implements a form of gain control that may be important for regulating runaway excitation in recurrently connected structures like the neocortex (Douglas et al., 1995). Conversely, spike-frequency acceleration may transiently enhance the gain with which active groups of motor cortical neurons respond to their inputs. Interestingly, recordings from motor cortex in behaving monkeys reveal that, in $\sim 20 \%$ of units, firing rate increases over hundreds of milliseconds and is related superlinearly to movement trajectory (Paninski et al., 2004) in a manner very reminiscent of the spike-frequency acceleration that we observe in $\sim 20 \%$ of M1 layer V pyramidal cells. It is tempting to speculate that this activity is generated by the same population of PT-projecting units that exhibit "warm-up firing" (Cheney and Fetz, 1980), and the acceleration described here is well suited to account for the superlinear gain increase with time observed in vivo. More generally, spike-frequency acceleration might act to increase correlations among synaptically coupled populations and thereby provide a substrate for a "winner-takeall" mechanism for motor program selection, since simulation studies indicate that the opposite process, spike-frequency adaptation, implements a form of decorrelation (Wang et al., 2003).

It is increasingly clear that neocortical microcircuitry is composed of diverse cell types whose properties vary both across cortical laminae and even between cells of the same lamina with different projection targets (Hattox and Nelson, 2007). The extent to which basic features of cortical organization are conserved across cortical areas, however, remains a matter of debate. Our discovery that spike-frequency acceleration is specific to a discrete population of layer 5 pyramidal cells and is further restricted to a particular cortical region provides important insight into this issue by establishing that features as basic as neuronal intrinsic membrane properties can be region specific, and thus supports the view that regional specialization of circuitry contributes to regional specialization of function.

\section{References}

Adamson CL, Reid MA, Mo ZL, Bowne-English J, Davis RL (2002) Firing features and potassium channel content of murine spiral ganglion neurons vary with cochlear location. J Comp Neurol 447:331-350.

Bekele-Arcuri Z, Matos MF, Manganas L, Strassle BW, Monaghan MM, Rhodes KJ, Trimmer JS (1996) Generation and characterization of subtype-specific monoclonal antibodies to $\mathrm{K}+$ channel alpha- and betasubunit polypeptides. Neuropharmacology 35:851-865.

Bekkers JM, Delaney AJ (2001) Modulation of excitability by alphadendrotoxin-sensitive potassium channels in neocortical pyramidal neurons. J Neurosci 21:6553-6560.

Benavides-Piccione R, Ballesteros-Yáñez I, DeFelipe J, Yuste R (2002) Cortical area and species differences in dendritic spine morphology. J Neurocytol 31:337-346.

Bevan MD, Wilson CJ (1999) Mechanisms underlying spontaneous oscilla- 
tion and rhythmic firing in rat subthalamic neurons. J Neurosci 19:7617-7628.

Bowlby MR, Fadool DA, Holmes TC, Levitan IB (1997) Modulation of the Kv1.3 potassium channel by receptor tyrosine kinases. J Gen Physiol 110:601-610.

Brew HM, Forsythe ID (1995) Two voltage-dependent $\mathrm{K}^{+}$conductances with complementary functions in postsynaptic integration at a central auditory synapse. J Neurosci 15:8011-8022.

Brew HM, Hallows JL, Tempel BL (2003) Hyperexcitability and reduced low threshold potassium currents in auditory neurons of mice lacking the channel subunit Kv1.1. J Physiol 548:1-20.

Castro-Alamancos MA (2000) Origin of synchronized oscillations induced by neocortical disinhibition in vivo. J Neurosci 20:9195-9206.

Castro-Alamancos MA, Tawara-Hirata Y (2007) Area-specific resonance of excitatory networks in neocortex: control by outward currents. Epilepsia 48:1572-1584.

Castro-Alamancos MA, Rigas P, Tawara-Hirata Y (2007) Resonance (approximately $10 \mathrm{~Hz}$ ) of excitatory networks in motor cortex: effects of voltage-dependent ion channel blockers. J Physiol 578:173-191.

Cheney PD, Fetz EE (1980) Functional classes of primate corticomotoneuronal cells and their relation to active force. J Neurophysiol 44:773-791.

Coetzee WA, Amarillo Y, Chiu J, Chow A, Lau D, McCormack T, Moreno H, Nadal MS, Ozaita A, Pountney D, Saganich M, Vega-Saenz de Miera E, Rudy B (1999) Molecular diversity of K+ channels. Ann N Y Acad Sci 868:233-285.

Cowan RL, Wilson CJ (1994) Spontaneous firing patterns and axonal projections of single corticostriatal neurons in the rat medial agranular cortex. J Neurophysiol 71:17-32.

Derjean D, Bertrand S, Le Masson G, Landry M, Morisset V, Nagy F (2003) Dynamic balance of metabotropic inputs causes dorsal horn neurons to switch functional states. Nat Neurosci 6:274-281.

Dodson PD, Barker MC, Forsythe ID (2002) Two heteromeric Kvl potassium channels differentially regulate action potential firing. J Neurosci 22:6953-6961.

Donoghue JP, Wise SP (1982) The motor cortex of the rat: cytoarchitecture and microstimulation mapping. J Comp Neurol 212:76-88.

Douglas RJ, Martin KA (2004) Neuronal circuits of the neocortex. Annu Rev Neurosci 27:419-451.

Douglas RJ, Koch C, Mahowald M, Martin KA, Suarez HH (1995) Recurrent excitation in neocortical circuits. Science 269:981-985.

Elston GN (2000) Pyramidal cells of the frontal lobe: all the more spinous to think with. J Neurosci 20:RC95(1-4).

Elston GN (2002) Cortical heterogeneity: implications for visual processing and polysensory integration. J Neurocytol 31:317-335.

Elston GN, DeFelipe J (2002) Spine distribution in cortical pyramidal cells: a common organizational principle across species. Prog Brain Res 136:109-133.

Fadool DA, Levitan IB (1998) Modulation of olfactory bulb neuron potassium current by tyrosine phosphorylation. J Neurosci 18:6126-6137.

Feng G, Mellor RH, Bernstein M, Keller-Peck C, Nguyen QT, Wallace M, Nerbonne JM, Lichtman JW, Sanes JR (2000) Imaging neuronal subsets in transgenic mice expressing multiple spectral variants of GFP. Neuron 28:41-51.

Finnegan TF, Chen SR, Pan HL (2006) Mu opioid receptor activation inhibits GABAergic inputs to basolateral amygdala neurons through Kv1.1/1.2 channels. J Neurophysiol 95:2032-2041.

Franklin KBJ, Paxinos G (2003) The mouse brain in stereotactic coordinates, Ed 3. New York: Academic.

Garcia-Calvo M, Leonard RJ, Novick J, Stevens SP, Schmalhofer W, Kaczorowski GJ, Garcia ML (1993) Purification, characterization, and biosynthesis of margatoxin, a component of Centruroides margaritatus venom that selectively inhibits voltage-dependent potassium channels. J Biol Chem 268:18866-18874.

Guan D, Lee JC, Tkatch T, Surmeier DJ, Armstrong WE, Foehring RC (2006) Expression and biophysical properties of Kv1 channels in supragranular neocortical pyramidal neurones. J Physiol 571:371-389.

Guan D, Lee JC, Higgs MH, Spain WJ, Foehring RC (2007) Functional roles of Kv1 channels in neocortical pyramidal neurons. J Neurophysiol 97:1931-1940.

Haider B, Duque A, Hasenstaub AR, McCormick DA (2006) Neocortical network activity in vivo is generated through a dynamic balance of excitation and inhibition. J Neurosci 26:4535-4545.
Hattox AM, Nelson SB (2007) Layer V neurons in mouse cortex projecting to different targets have distinct physiological properties. J Neurophysiol 98:3330-3340.

Hempel CM, Hartman KH, Wang XJ, Turrigiano GG, Nelson SB (2000) Multiple forms of short-term plasticity at excitatory synapses in rat medial prefrontal cortex. J Neurophysiol 83:3031-3041.

Hopkins WF (1998) Toxin and subunit specificity of blocking affinity of three peptide toxins for heteromultimeric, voltage-gated potassium channels expressed in Xenopus oocytes. J Pharmacol Exp Ther 285:1051-1060.

Hopkins WF, Allen ML, Houamed KM, Tempel BL (1994) Properties of voltage-gated $\mathrm{K}+$ currents expressed in Xenopus oocytes by mKv1.1, mKv1.2 and their heteromultimers as revealed by mutagenesis of the dendrotoxin-binding site in mKv1.1. Pflugers Arch 428:382-390.

Isacoff EY, Jan YN, Jan LY (1990) Evidence for the formation of heteromultimeric potassium channels in Xenopus oocytes. Nature 345:530-534.

Jan LY, Jan YN (1992) Structural elements involved in specific K+ channel functions. Annu Rev Physiol 54:537-555.

Kaczorowski CC, Disterhoft J, Spruston N (2007) Stability and plasticity of intrinsic membrane properties in hippocampal CA1 pyramidal neurons: effects of internal anions. J Physiol 578:799-818.

Kole MH, Letzkus JJ, Stuart GJ (2007) Axon initial segment Kv1 channels control axonal action potential waveform and synaptic efficacy. Neuron 55:633-647.

La Camera G, Rauch A, Thurbon D, Lüscher HR, Senn W, Fusi S (2006) Multiple time scales of temporal response in pyramidal and fast spiking cortical neurons. J Neurophysiol 96:3448-3464.

Manganas LN, Trimmer JS (2000) Subunit composition determines Kv1 potassium channel surface expression. J Biol Chem 275:29685-29693.

Metin C, Frost DO (1989) Visual responses of neurons in somatosensory cortex of hamsters with experimentally induced retinal projections to somatosensory thalamus. Proc Natl Acad Sci U S A 86:357-361.

Mo ZL, Adamson CL, Davis RL (2002) Dendrotoxin-sensitive K(+) currents contribute to accommodation in murine spiral ganglion neurons. J Physiol 542:763-778.

Morishima M, Kawaguchi Y (2006) Recurrent connection patterns of corticostriatal pyramidal cells in frontal cortex. J Neurosci 26:4394-4405.

Myme CI, Sugino K, Turrigiano GG, Nelson SB (2003) The NMDA-toAMPA ratio at synapses onto layer $2 / 3$ pyramidal neurons is conserved across prefrontal and visual cortices. J Neurophysiol 90:771-779.

Nelson S (2002) Cortical microcircuits: diverse or canonical? Neuron 36:19-27.

Paninski L, Shoham S, Fellows MR, Hatsopoulos NG, Donoghue JP (2004) Superlinear population encoding of dynamic hand trajectory in primary motor cortex. J Neurosci 24:8551-8561.

Po S, Roberds S, Snyders DJ, Tamkun MM, Bennett PB (1993) Heteromultimeric assembly of human potassium channels. Molecular basis of a transient outward current? Circ Res 72:1326-1336.

Porter JT, Cauli B, Staiger JF, Lambolez B, Rossier J, Audinat E (1998) Properties of bipolar VIPergic interneurons and their excitation by pyramidal neurons in the rat neocortex. Eur J Neurosci 10:3617-3628.

Rasband MN, Trimmer JS, Schwarz TL, Levinson SR, Ellisman MH, Schachner M, Shrager P (1998) Potassium channel distribution, clustering, and function in remyelinating rat axons. J Neurosci 18:36-47.

Rettig J, Heinemann SH, Wunder F, Lorra C, Parcej DN, Dolly JO, Pongs O (1994) Inactivation properties of voltage-gated $\mathrm{K}+$ channels altered by presence of beta-subunit. Nature 369:289-294.

Rhodes KJ, Keilbaugh SA, Barrezueta NX, Lopez KL, Trimmer JS (1995) Association and colocalization of $\mathrm{K}^{+}$channel $\alpha$ - and $\beta$-subunit polypeptides in rat brain. J Neurosci 15:5360-5371.

Rhodes KJ, Strassle BW, Monaghan MM, Bekele-Arcuri Z, Matos MF, Trimmer JS (1997) Association and colocalization of the $\mathrm{Kv} \beta 1$ and $\mathrm{Kv} \beta 2$ $\beta$-subunits with Kv1 $\alpha$-subunits in mammalian brain $\mathrm{K}^{+}$channel complexes. J Neurosci 17:8246-8258.

Ruppersberg JP, Schröter KH, Sakmann B, Stocker M, Sewing S, Pongs O (1990) Heteromultimeric channels formed by rat brain potassiumchannel proteins. Nature 345:535-537.

Sanchez-Vives MV, McCormick DA (2000) Cellular and network mechanisms of rhythmic recurrent activity in neocortex. Nat Neurosci 3:1027-1034.

Schwindt PC, Spain WJ, Foehring RC, Chubb MC, Crill WE (1988) Slow conductances in neurons from cat sensorimotor cortex in vitro and their role in slow excitability changes. J Neurophysiol 59:450-467. 
Schwindt PC, Spain WJ, Crill WE (1992) Effects of intracellular calcium chelation on voltage-dependent and calcium-dependent currents in cat neocortical neurons. Neuroscience 47:571-578.

Sewing S, Roeper J, Pongs O (1996) Kv beta 1 subunit binding specific for shaker-related potassium channel alpha subunits. Neuron 16:455-463.

Shen W, Hernandez-Lopez S, Tkatch T, Held JE, Surmeier DJ (2004) Kv1.2containing $\mathrm{K}+$ channels regulate subthreshold excitability of striatal medium spiny neurons. J Neurophysiol 91:1337-1349.

Shu Y, Yu Y, Yang J, McCormick DA (2007) Selective control of cortical axonal spikes by a slowly inactivating $\mathrm{K}+$ current. Proc Natl Acad Sci U S A 104:11453-11458.

Spain WJ, Schwindt PC, Crill WE (1991a) Two transient potassium currents in layer $\mathrm{V}$ pyramidal neurones from cat sensorimotor cortex. J Physiol 434:591-607.

Spain WJ, Schwindt PC, Crill WE (1991b) Post-inhibitory excitation and inhibition in layer $\mathrm{V}$ pyramidal neurones from cat sensorimotor cortex. J Physiol 434:609-626.

Steriade M, Nuñez A, Amzica F (1993) A novel slow ( $<1 \mathrm{~Hz}$ ) oscillation of neocortical neurons in vivo: depolarizing and hyperpolarizing components. J Neurosci 13:3252-3265.

Storm JF (1988) Temporal integration by a slowly inactivating K+ current in hippocampal neurons. Nature 336:379-381.

Stühmer W, Ruppersberg JP, Schröter KH, Sakmann B, Stocker M, Giese KP, Perschke A, Baumann A, Pongs O (1989) Molecular basis of functional diversity of voltage-gated potassium channels in mammalian brain. EMBO J 8:3235-3244.

Sugino K, Hempel CM, Miller MN, Hattox AM, Shapiro P, Wu C, Huang ZJ, Nelson SB (2006) Molecular taxonomy of major neuronal classes in the adult mouse forebrain. Nat Neurosci 9:99-107.

Sur M, Garraghty PE, Roe AW (1988) Experimentally induced visual projections into auditory thalamus and cortex. Science 242:1437-1441.

Toledo-Rodriguez M, Blumenfeld B, Wu C, Luo J, Attali B, Goodman P, Markram H (2004) Correlation maps allow neuronal electrical properties to be predicted from single-cell gene expression profiles in rat neocortex. Cereb Cortex 14:1310-1327.
Turrigiano GG, Marder E, Abbott LF (1996) Cellular short-term memory from a slow potassium conductance. J Neurophysiol 75:963-966.

Veh RW, Lichtinghagen R, Sewing S, Wunder F, Grumbach IM, Pongs O (1995) Immunohistochemical localization of five members of the Kvl channel subunits: contrasting subcellular locations and neuron-specific co-localizations in rat brain. Eur J Neurosci 7:2189-2205.

Villalobos C, Shakkottai VG, Chandy KG, Michelhaugh SK, Andrade R (2004) SKCa channels mediate the medium but not the slow calciumactivated afterhyperpolarization in cortical neurons. J Neurosci 24:3537-3542.

Wang H, Kunkel DD, Schwartzkroin PA, Tempel BL (1994) Localization of Kv1.1 and Kv1.2, two K channel proteins, to synaptic terminals, somata, and dendrites in the mouse brain. J Neurosci 14:4588-4599.

Wang XJ, Liu Y, Sanchez-Vives MV, McCormick DA (2003) Adaptation and temporal decorrelation by single neurons in the primary visual cortex. J Neurophysiol 89:3279-3293.

Wang Y, Markram H, Goodman PH, Berger TK, Ma J, Goldman-Rakic PS (2006) Heterogeneity in the pyramidal network of the medial prefrontal cortex. Nat Neurosci 9:534-542.

Werkman TR, Gustafson TA, Rogowski RS, Blaustein MP, Rogawski MA (1993) Tityustoxin-K alpha, a structurally novel and highly potent K+ channel peptide toxin, interacts with the alpha-dendrotoxin binding site on the cloned Kv1.2 K+ channel. Mol Pharmacol 44:430-436.

Williams SR, Mitchell SJ (2008) Direct measurement of somatic voltage clamp errors in central neurons. Nat Neurosci 11:790-798.

Wilson CJ, Weyrick A, Terman D, Hallworth NE, Bevan MD (2004) A model of reverse spike frequency adaptation and repetitive firing of subthalamic nucleus neurons. J Neurophysiol 91:1963-1980.

Wu RL, Barish ME (1992) Two pharmacologically and kinetically distinct transient potassium currents in cultured embryonic mouse hippocampal neurons. J Neurosci 12:2235-2246.

Zhang L, Weiner JL, Valiante TA, Velumian AA, Watson PL, Jahromi SS, Schertzer S, Pennefather P, Carlen PL (1994) Whole-cell recording of the $\mathrm{Ca}(2+)$-dependent slow afterhyperpolarization in hippocampal neurones: effects of internally applied anions. Pflugers Arch 426:247-253. 